\title{
Diurnal Changes in the Leucogram of Ovariectomized Gilts
}

Recognition of diurnal variations in physiological systems is essential for correct interpretation of physiological and pathological changes in animals. This study shows diurnal changes in the leucogram over the day for adult pigs.

The study comprised 8 healthy crossbred (Landrace $\mathrm{x}$ Yorkshire $\mathrm{x}$ Hampshire) ovariectomized gilts at an age of 10 months. The gilts had long time intravenous catheters placed in the jugular vein and held in individual pens at the clinic. The study was performed on the 10th day after catheter-operation. Blood was collected at $9 \mathrm{am}, 12$ noon, $3 \mathrm{pm}$, $5 \mathrm{pm}$ and $8 \mathrm{pm}$ in tubes containing EDTA. In these tubes, the total number of leucocytes and the number of lymphocytes and neutrophils number per liter blood were counted. Cortisol was determined in plasma from the heparinized blood-samples collected by the same scheme as for the leucocyte counts, but 8 days after the operation. The cortisol levels were determined by a radioimmunoassy according to Nyberg et al. (1988). The analyses in blood were performed at the Department of Clinical Chemistry, Swedish University of Agricultural Sciences.

The least square means of the leucocyte numbers obtained from an analysis of variance are presented in Figure 1. The total number of leucocytes was signigicantly lower $(\mathrm{p}<0.05)$ at 9 am $\left(16.7 \times 10^{9} /\right.$ litre $)$ than at noon
( $18.7 \times 10^{9} /$ litre $)$ and at $8 \mathrm{pm}\left(18.6 \times 10^{9} /\right.$ litre $)$. The number of lymphocytes decreased significantly $(\mathrm{p}<0.05)$ from noon $\left(11.5 \times 10^{9} /\right.$ litre $)$ to $3 \mathrm{pm}\left(9.7 \times 10^{9} /\right.$ litre $)$. The number of neutrophils increased steadily over the day giving a significant difference $(\mathrm{p}<0.05)$ between the $5.0 \times 10^{9}$ cells/litre at 9 am and the $6.5 \times 10^{9}$ cells/litre at $8 \mathrm{pm}$.

The least square means of the plasma level of cortisol were higher in the samples collected at 9 am and 12 noon (41 and $45 \mathrm{nmol} / 1$, respectively) than in the samples collected 5 $\mathrm{pm}$ and $8 \mathrm{pm}(15$ and $25 \mathrm{nmol} / \mathrm{l}$, respectively). This difference was statistically significant $(\mathrm{p}<0.05)$ when comparing the 9 am and 12 noon levels with the $5 \mathrm{pm}$ levels.

Diurnal variation in the leucogram has been described in mouse (Brown \& Dougherty 1956) and man (Bartter et al. 1962). In these studies, the diurnal variations has been related to the plasma concentrations of corticosteriods. In the present study, the diurnal change in the plasma level of cortisol, high levels in the morning and low in the evening, are in accordance with other studies in ovariectomized gilts (Becker et al. 1985). In general, high cortisol levels in plasma increase the number of neutrophils in the circulation an decrease that of lymphocytes (Fauci 1979). This was not the case in the present study. In the evening, the neutrophil number was high and the lymphocyte number was low. This 


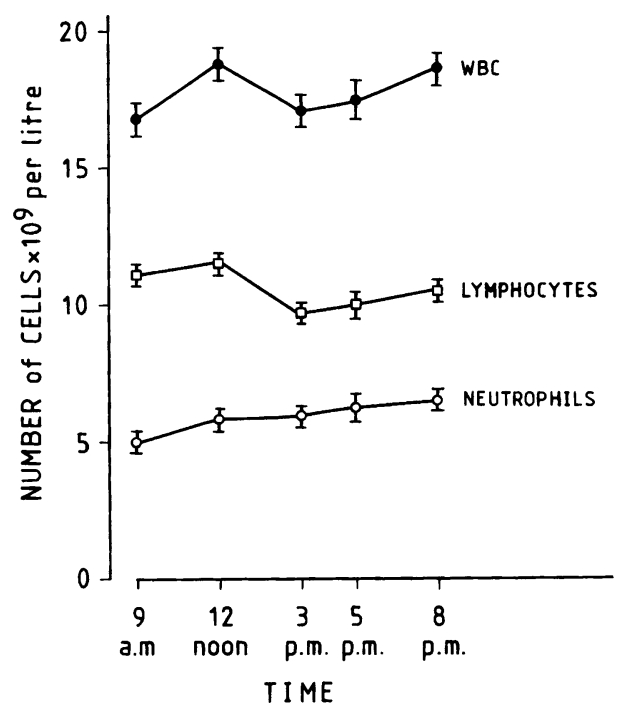

Figure 1. The number of total white blood cells (-—), lymphocytes ( $\square-\square$ ) and neutrophils $(\mathrm{O}-\mathrm{O})$ per litre blood over the day (Least-squares mean and s.e.m., $\mathrm{n}=8$ ).

finding indicates that there may be other factors but corticosteroids that contribute to the diurnal changes in the leucogram of pigs. However, the present study stress the importance of considering the time of blood collection when interpreting data on the leucogram of pigs in research.

\section{Acknowledgements}

This study was supported by the Swedish Council for Forestry and Agricultural Research.

\section{U. Magnusson and A. -M. Dalin}

Department of Obstetrics and Gynaecology, P.O Box 7039, Swedish University of Agricultural Sciences, S- 75007 Uppsala, Sweden.

\section{References}

Bartter FC, Delea CS, Halberg F: A map of blood and urinary changes related to circadian variations in adrenal cortical function in normal subjects. Ann. N. Y. Acad. Sci. 1962, 969-983.

Becker BA, Ford JJ, Christenson RK, Manak RC, Hahn GL, DeShazer JA: Cortisol response of gilts in tether stalls. J. Anim. Sci. 1985, 60, 264270.

Brown HE, Dougherty TF: The diurnal variation of blood leukocytes in normal and adrenalectomized mice. Endocrinology 1956, 58, 365-375.

Fauci AS: Immunosuppressive and anti-inflammatory effects of glucocorticoids. Monograph. Endocrin. 1979, 12, 449-465.

Nyberg L, Lundström K, Edfors-Lilja I, Rundgren $M$ : Effects of transport stress on concentrations of cortisol, corticosteroid-binding globulin and glucocorticoid receptors in pigs with different halothane genotypes. J. Anim. Sci. 1988, 66, 1201-1211.

(Recived December 10, 1991; accepted January 6, 1992).

Reprints may be requested from: U. Magnusson, Department of Obstetrics and Gynaecology, P.O. Box 7039, Swedish University of Agricultural Sciences, S-750 07 Uppsala, Sweden. 